\title{
具有不同长度间隔基的含联苯基团的侧链液晶聚炔的苂光行为
}

\author{
余振强 ${ }^{1,2, *}$ 张 昕 ${ }^{1}$ 李子臣 ${ }^{1}$ 陈尔强 ${ }^{1, *}$ \\ LAM Jacky W. Y. ${ }^{3}$ 唐本忠 ${ }^{3}$ \\ ( ${ }^{1}$ 北京大学化学与分子工程学院高分子科学与工程系, 高分子化学与物理教育部重点实验室, 北京分子科学国家实验室, 北京 \\ 100871; 2 深圳大学化学与化工学院, 深圳市功能高分子重点实验室, 广东 深圳 $518060 ; 3$ 香港科技大学化学系, 香港九龙)
}

\begin{abstract}
摘要：对一系列具有不同长度间隔基的含联苯基团的侧链液晶聚炔的稳态荧光和苂光衰减行为进行了研究. 为便于比较, 选取其中一个单体作为模型化合物. 稳态苂光光谱结果表明, 聚合物和单体均显示一个苂光发射, 该苂光发射来源于聚合物侧链的联苯基团. 随着间隔基长度的减小, 聚合物的菼光强度降低. 菼光衰减结果表明 单体的苂光衰减可以拟合为一个单指数衰减, 而聚合物的苂光衰减拟合为三指数衰减. 这种三指数衰减可能由 溶液局部高浓度引起的猝灭和侧链联苯基团的旋转受阻所引起. 溶剂效应表明, 溶剂与联苯基团之间的相互作 用随溶剂极性增加而增大.
\end{abstract}

关键词：稳态苂光；单取代聚炔；联苯；苂光寿命；溶剂效应 中图分类号: 0644

\section{Fluorescence Behavior of Biphenyl Containing Side-Chain Liquid Crystalline Polyacetylene with Various Lengths of Spacers}

\author{
YU Zhen-Qiang ${ }^{1,2, *} \quad$ ZHANG Xin ${ }^{1} \quad$ LI Zi-Chen $^{1} \quad$ CHEN Er-Qiang ${ }^{1, *}$ \\ LAM Jacky W. Y. ${ }^{3} \quad$ TANG Ben-Zhong ${ }^{3}$ \\ ('Beijing National Laboratory for Molecular Sciences, Key Laboratory of Polymer Chemistry and Physics of the Ministry of Education, \\ Department of Polymer Science and Engineering, College of Chemistry and Molecular Engineering, Peking University, Beijing \\ 100871, P. R. China; ${ }^{2}$ School of Chemistry and Chemical Engineering and Shenzhen Key Laboratory of Functional Polymers, \\ Shenzhen University, Shenzhen 518060, Guangdong Province, P. R. China; ${ }^{3}$ Department of Chemistry, The Hong Kong \\ University of Science \& Technology, Kowloon, Hong Kong, P. R. China)
}

\begin{abstract}
Steady state fluorescence and fluorescence decay of a series of monosubstituted biphenyl containing sidechain liquid crystalline polyacetylenes with different lengths of spacers were investigated. For comparison, a monomer was selected as a model compound. Steady state fluorescence spectra elucidated that the polymers and the monomer showed single fluorescence emission arising from the biphenyl group on the side chain. With decreasing the length of the spacer, the fluorescence intensity of the polymer decreased accordingly. The fluorescence decay showed that the decay of the monomer could be fitted to be a single-exponential decay, while that of the polymers should be fitted to be a triple-exponential decay, which may be originated from the local high concentration induced quenching and the rotational restriction of the side-chain biphenyl groups. Solvent effects illustrated that the interaction between the solvents and the biphenyl groups strengthened with increasing the polarity of the solvents.
\end{abstract}

Key Words: Steady state fluorescence; Monosubstituted polyacetylene; Biphenyl; Fluorescence lifetime; Solvent effect

Received: May 13, 2010; Revised: July 8, 2010; Published on Web: July 9, 2010.

"Corresponding authors. YU Zhen-Qiang, Email: zqyu@ szu.edu.cn; Tel: +86-755-26535427. CHEN Er-Qiang, Email: eqchen@pku.edu.cn; Tel: +86-10-62753370

The project was supported by the National Natural Science Foundation of China (20129001), the Research Grants Council of Hong Kong, China (CA05/06.SC02) and R/D Fund of Shenzhen University, China (200824).

国家自然科学基金(20129001), 香港研究资助局(CA05/06.SC02)和深圳大学青年基金(200824)资助项目

(C) Editorial office of Acta Physico-Chimica Sinica 
The discovery of electroluminescence of poly ( $p$-phenylenevinylene $)^{[1]}$ in 1990 has aroused wide interest of the application of conjugated polymers in the field of light-emitting and optoelectronics ${ }^{[2-3]}$. To develop advanced materials with high quantum yield and high performance, many efforts have been directed toward molecular design and materials processing. Polyacetylene is a prototypical conjugated polymer, which has been intensively studied for decades ${ }^{[4-5]}$. Polyacetylene with an extremely low solubility does not exhibit efficient luminescence properties $^{[6-7]}$. To achieve desirable photochemical and photophysical properties, mono- or di-substituted polyacetylenes with the sidechain containing appropriate chromophores have been designed; and their photoluminescence and/or aggregation induced emission behaviors have been studied ${ }^{[8-12]}$. Considering improving and controlling the properties of substituted poly-acetylenes, the following four factors should be taken into account ${ }^{[13]}$ : the configuration and regularity of the main chain, the nature of the substituent, the steric interaction of the side chain, and the degree of the conjugation. Among them, the forth factor, i.e., the conjugation length of main chain may play an important role. However, the side-chain structure and the mode of how the sidechains are linked to the polyacetylene backbone in fact can greatly affect the conjugation length.

The biphenyl moieties are often employed as a building block for the fabrication of various luminescent materials ${ }^{[14-15]}$. Tang and his co-workers have synthesized a series of mono- and bisubstituted biphenyl containing polyacetylenes ${ }^{[16-19]}$, and have studied the samples' phase behaviors ${ }^{[20-22]}$, light emitting behaviors $^{[23-24]}$, and aggregation behaviors in dilute solutions ${ }^{[2]]}$. Some of the samples are found to be highly luminescent. The biphenyl group is also a typical mesogenic core. Usually, it is terminally attached to the polyacetylene backbone through a flexible spacer $^{[15-16,20]}$. In this regard, the resultant polymer belongs to the family of side-chain liquid crystalline polyacetylenes (SCLCPAs). In this paper, we intend to study the spacer length dependence of the genuine fluorescence property of a monosubstituted SCLCPA, namely, poly $\left((m+2)-\left\{\left[\left(4^{\prime}\right.\right.\right.\right.$-heptyloxy-4-biphenylyl $)$ carbonyl]oxy\}-1-alkylyne) (abbreviated as P- $m, 7$, where $m$ is the number of the methylene units of the spacer, and the number 7 represents the carbon number of the side-chain tail, see Scheme 1). The steady state and time-resolved fluorescence behavior of P- $m, 7$ were studied in comparison with that of a monomer (M3,7 , see Scheme 1) used as a model compound. The solvent effect in various solvents with different polarities was also investigated

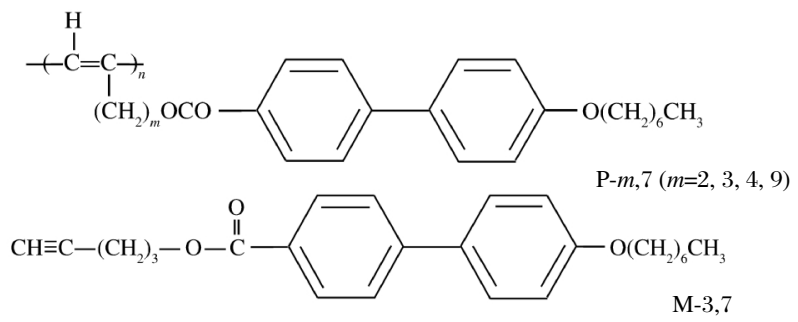

Scheme 1 Chemical structures of P- $m, 7(m=2,3,4,9)$ and $\mathrm{M}-3,7$ to elucidate the interaction between the polymers and the solvents.

\section{Experimental}

\subsection{Materials}

The syntheses of P- $m, 7$ and the corresponding monomers have been published ${ }^{[26]}$. In brief, using $\mathrm{WCl}_{6}-\mathrm{Ph}_{4} \mathrm{Sn}$ as a catalyst tolerant of the functional groups on the substitutes of the acetylene monomers, the solution polymerization under optimal conditions yielded the polymers with moderate to high molecular weights (MW). According to the result of ${ }^{1} \mathrm{H}$ NMR analysis, the resultant polymers with good stereoregularity are trans-rich (the transcontents are determined to be $>80 \%$ ). Table 1 lists the apparent number-average molecular weight $\left(M_{\mathrm{n}}\right)$ and the polydispersity index (PDI) of the samples used in this study.

All the solvents used for the measurements of UV-Vis and fluorescence spectra were high performance liquid chromatography (HPLC) grade and were used as received. The stock solutions were prepared by directly dissolving the polymers (or the monomer) in chloroform (C), tetrahydrofuran (THF), dichloromethane (DCM), and acetonitrile (AN). Usually, dodecane (D) is considered as a poor solvent for P- $m, 7$. We prepared the dodecane solutions of $\mathrm{P}-m, 7$ with a concentration much lower than the critical aggregation concentration. In preparation, a calculated amount of the concentrated chloroform stock solution was added dropwise into dodecane under vigorous stirring. Since the amount of chloroform is little, its influence can be omitted.

\subsection{Measurements}

UV-Vis absorption spectra were recorded on a Shimadzu UV2101 spectrophotometer. The steady-state fluorescence spectra were acquired on a Hitachi F-4500 fluorescence spectrophotometer at room temperature. The slit widths of monochromators for excitation and emission were 10.0 and $5.0 \mathrm{~nm}$, respectively. The time-resolved fluorescence measurements were performed using the time-correlated single-photo counting (TCSPC) technique following excitation by a nanosecond flash lamp (Edinburg Instruments FL900). Fluorescence decay curves were analyzed using the least-squares interactive convolution method.

\section{Results and discussion}

\subsection{UV-Vis absorption and steady state fluorescence spectra}

Fig. 1(a) shows the UV-Vis absorption spectra of P- $m, 7$ and M-3,7 in chloroform with a concentration of $4 \times 10^{-6} \mathrm{~g} \cdot \mathrm{mol}^{-1}$. The absorption band peaked at $295 \mathrm{~nm}$ can be assigned to the $\pi-\pi$ transition of the aromatic biphenyl group. However, no clear ab-

Table 1 Molecular characteristics of the P-m,7 samples

\begin{tabular}{ccc}
\hline Sample & $10^{-4} M_{\mathrm{n}} /\left(\mathrm{g} \cdot \mathrm{mol}^{-1}\right)^{\text {a }}$ & PDI \\
\hline P-2,7 & 4.08 & 2.22 \\
P-3,7 & 4.99 & 2.25 \\
P-4,7 & 11.29 & 5.01 \\
P-9,7 & 4.12 & 2.21 \\
\hline
\end{tabular}

${ }^{a}$ The apparent number-average molecular weight $M_{\mathrm{n}}$ was measured by gel permeation chromatography (GPC) with the calibration using polystyrene standards. 

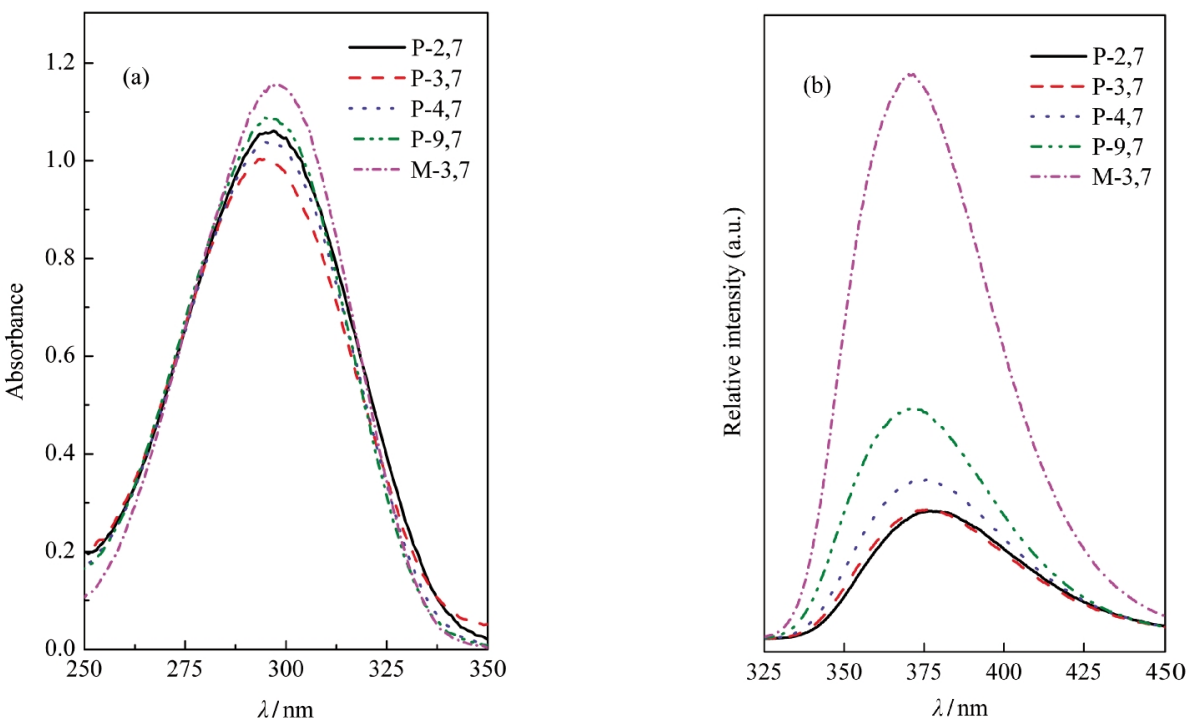

Fig.1 (a) UV-Vis absorption and (b) steady state fluorescence spectra of P- $m, 7(m=2,3,4,9)$ in chloroform For comparison, the spectra of M-3,7 in chloroform are also included. For the fluorescence measurement, the excitation wavelength $\lambda_{\mathrm{ex}}=300 \mathrm{~nm}$.

sorption band at longer wavelength is observed, which implies that the conjugation length of the polyacetylene main chain is not long enough in solutions. The same results can also be obtained in other good solvents, such as tetrahydrofuran, dichloromethane, acetonitrile, and in the poor solvent of dodecane.

Fig.1(b) depicts the fluorescence spectra of the monomer and the polymers dissolved in chloroform with a concentration of $1 \times$ $10^{-5} \mathrm{~mol} \cdot \mathrm{L}^{-1}$ (the molar concentration of the polymer solutions was calculated on the basis of the repeating unit). The spectral shapes of the P-m, 7 are found to be almost the same as that of M-3,7, wherein a single emission peak without fine structure is observed. This indicates that the fluorescence emission of the polymers is mainly originated from the side-chain biphenyl group. With regard to the wavelength of emission peak, the effect of the flexible spacer length is not severe. For M-3,7 and the polymer with the longest alkyl spacer (P-9,7), the emission peak locates at $371 \mathrm{~nm}$, while the other three samples present the maximum emission wavelength at $377 \mathrm{~nm}$. In comparison with that of M-3,7, the red-shift observed for the P-2,7, P-3,7, and P-4,7 may be due to the coupling between the side-chain biphenyl group and the polyacetylene backbone. On the other hand, Fig. $1 b$ shows that when the methylene unit number (i.e., the number $m$ ) of the spacer of P- $m, 7$ is decreased from 9 to 2 , the fluorescence intensity decreases accordingly. The calculated fluorescence quantum yields in chloroform are $0.281,0.283,0.344$, and 0.480 for P-2,7, P-3,7, P-4,7, and P-9,7 with 9,10-diphenylanthracene as the reference, respectively, which are in accordance with the fluores-cence intensity results. Note that the biphenyl groups are chemically linked to the polyacetylene backbone. Shortening the flexible spacer will increase the local concentration of biphenyl groups around the main chain and will restrict the side-chain motion to a certain extent ${ }^{[16]}$. Therefore, in addition to the fluorescence quenching due to the local concentration effect, P- $m, 7$ with shorter spacers can have a stronger resonance energy transfer which can further reduce the emission intensity.

\subsection{Solvent effects}

To gain an insight into the interaction between the biphenyl group and the solvent molecule, the fluorescence spectra of P- $m, 7$ in various solvents were measured. As an example, Fig.2(a) shows a set of normalized fluorescence spectra of P-3,7 solutions with a fixed concentration of $1 \times 10^{-5} \mathrm{~mol} \cdot \mathrm{L}^{-1}$. In principle, the solvent effects on the fluorescence emission can be quantitatively analyzed by using the Lippert-Matage equation as follows ${ }^{[27-29]}$ :

$$
\Delta \nu=\nu_{\mathrm{ab}}-\nu_{\mathrm{em}}=2 \Delta f\left(\mu_{\mathrm{E}}-\mu_{\mathrm{G}}\right)^{2} / h c a^{3}+\mathrm{constant}
$$

where $\Delta \nu$ is the Stokes shift; $\nu_{\mathrm{ab}}$ and $\nu_{\mathrm{em}}$ are the wavenumbers $\left(\mathrm{cm}^{-1}\right)$ of the absorption and emission, respectively; $\Delta f$ is the solvent parameter, which is termed as orientation polarizability $(\Delta f=$ $(\varepsilon-1) /(2 \varepsilon+1)-\left(n^{2}-1\right) /\left(2 n^{2}+1\right)$, where $\varepsilon$ and $n$ are the dielectric constant and the refractive index of solvents, respectively); $\mu_{\mathrm{C}}$ and $\mu_{\mathrm{E}}$ are the dipole moments of ground and excited states, respectively. Fig.2(b) gives the plots of the $\Delta \nu$ against $\Delta f$ for $\mathrm{P}-3,7$ and M-3,7 in the solvents of D, C, THF, DCM, and AN. The corresponding fitted results based on the Lippert-Matage equation are also included in Fig.2(b). Obviously, the Stokes shift becomes larger with increasing solvent polarity. This result suggests that the interaction between the solvent and fluorescence group is strengthened with increasing the $\Delta f$ of solvent, which subsequently causes a decrease of the excited state energy of fluorescent group. From these results, it is reasonable to conclude that the interaction between the solvent and the biphenyl group strengthens with increasing the solvent polarity.

\subsection{Lifetime measurements}

To get a better understanding of the fluorescence behavior of the polymers and the monomer, their fluorescence decays were measured by using a TCSPC technique. Fig. 3 gives the fluorescence decays and the residuals of $\mathrm{M}-3,7$ and $\mathrm{P}-3,7$ in chloroform, respectively. It is found that M-3,7 displays a single exponential decay with a emission lifetime $(\tau)$ of $1.44 \mathrm{~ns}$. But for the 

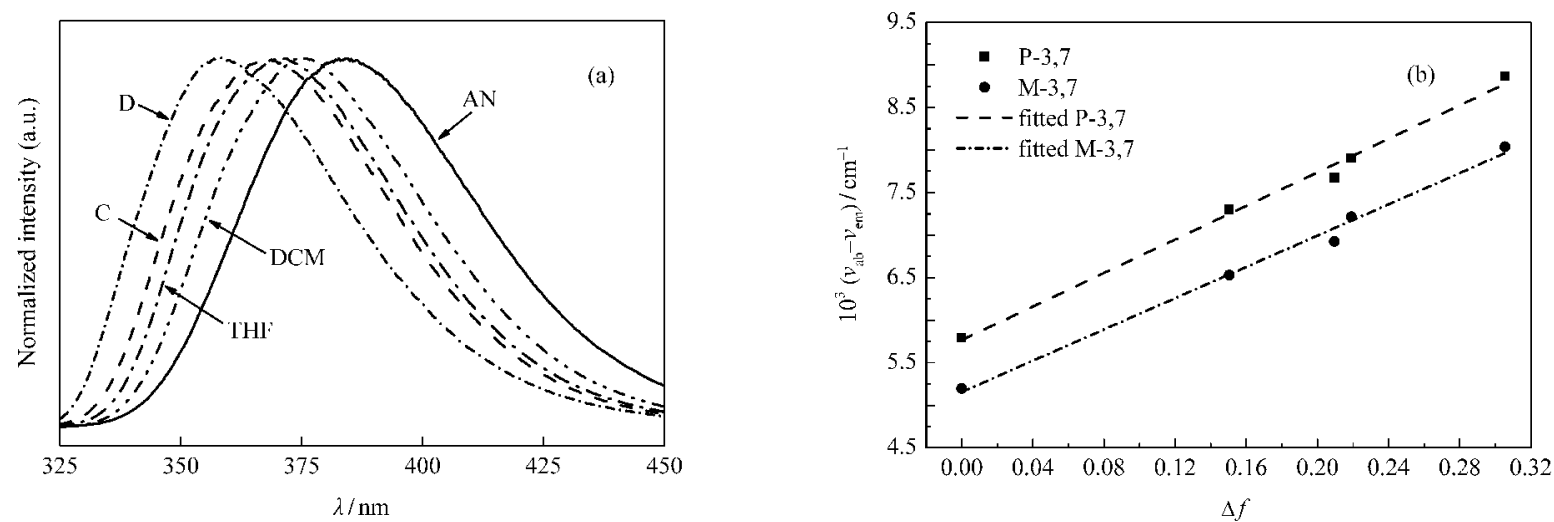

Fig.2 (a) Normalized emission spectra of P-3,7 in D, C, DCM, THF, and AN with the concentration of $1 \times 10^{-5} \mathrm{~mol}^{-1} \cdot \mathrm{L}^{-1}$;

(b) Lippert plots of $\Delta y v s \Delta f$

For dodecane (D), $\Delta f=0$; for chloroform (C), $\Delta f=0.1503$; for dichloroform (DCM), $\Delta f=0.2095$; for tetrahydrofuran (THF), $\Delta f=0.2191$; for acetonitrile (AN), $\Delta f=0.3054$. In (b), the data of M-3,7 are also included.

P-3,7 and also other three polymers, the following triple-exponential function can fit the decay behavior better than the single or double-exponential one does:

$y=A_{1} \mathrm{e}^{-t / \tau_{1}}+A_{2} \mathrm{e}^{-t / \tau_{2}}+A_{3} \mathrm{e}^{-t / \tau_{3}}$

This reveals that the excited states of the polymers decay through three pathways, namely, there exist three emission centers for the excited state of the polymers. The values of $A_{1}, A_{2}$, and $A_{3}$ in the function represent the fractions of the number of the molecules decaying in the three pathways. Table 2 summarizes the fitted data of fluorescence decay of M-3,7 and P- $m, 7$.
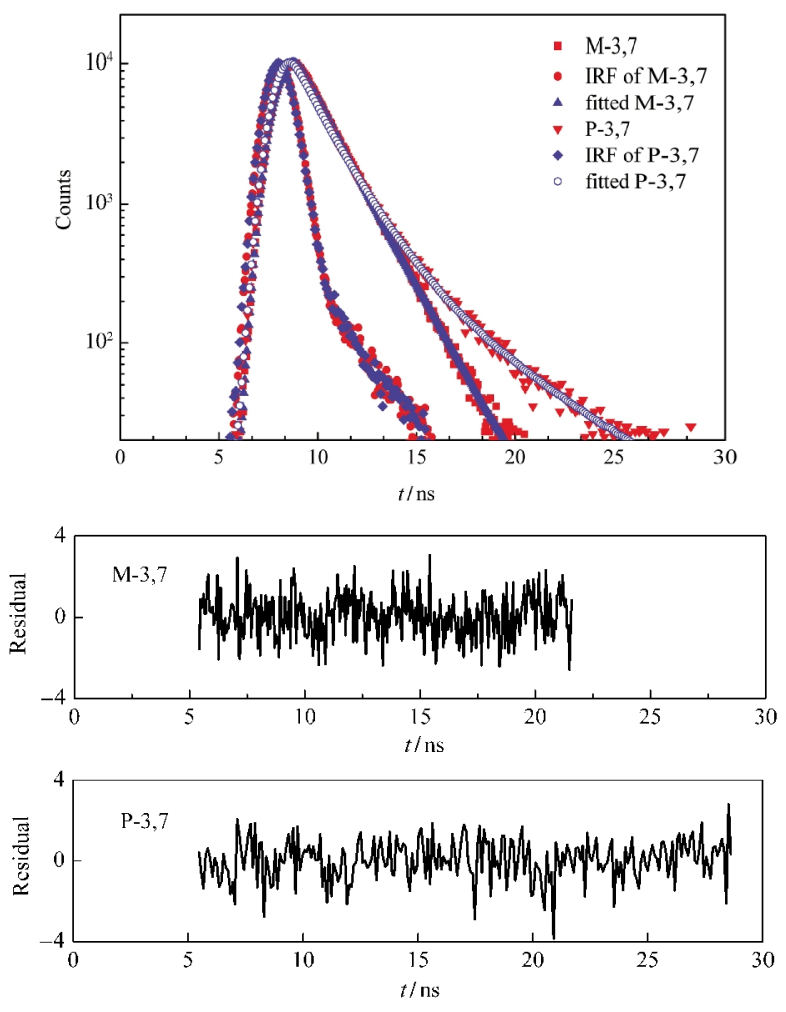

Fig.3 Fluorescence decay and the residuals of M-3,7 and $\mathbf{P}-3,7$ in chloroform

$\lambda_{\mathrm{ex}}=310 \mathrm{~nm}, \lambda_{\mathrm{em}}=371 \mathrm{~nm}$ for M-3,7 and $\lambda_{\mathrm{em}}=377 \mathrm{~nm}$ for P-3, 7 concentration: $1 \times 10^{-5} \mathrm{~mol} \cdot \mathrm{L}^{-1}$; IRF: instrument response function
For the monomer, the single carbon-carbon bond that links the two benzene rings can rotate freely in the dilute solution. Therefore, various conformations can be reached dynamically, giving a single exponential decay of fluorescence. While the biphenyl group is attached to the polyacetylene backbone as a pendant, the excited state energy transferring from the pendant to the backbone should be considered ${ }^{[30]}$. Different from the monomer, the rotation of biphenyl group on a side-chain is hindered due to the existences of neighboring side-chains and backbone. Therefore, the fluorescence decay of the polymers becomes complicated. The restricted rotation may result in a component of decay with longer lifetime ( $\tau_{3}$ in Table 2 ), which is $6.30,5.33$, 5.85, and 3.35 ns for P-2,7, P-3, 7, P-4,7, and P-9,7, respectively. It is conceivable that increasing the spacer length will decrease the rotational restriction, and thus the value of $\tau_{3}$ of P-9, 7 becomes smallest. Compared with that of P-4,7, the $\tau_{3}$ value of P3,7 is smaller, which might be originated from the odd-even effect of the flexible spacer. On the other hand, the fluorescence quenching due to the high local concentration of P- $m, 7$ may result in the fastest decay with a $\tau_{1}$ of $\sim 0.2 \mathrm{~ns}$. It is worth noting that the dominant lifetime $\left(\tau_{2}\right)$ of P- $m, 7$ is very close to that of the monomer, which corresponds to a fluorescence relaxation for the energy migration from higher to lower energy levels by the rotation of single carbon-carbon bond between the two benzene rings. We also calculated the mean lifetime $\tau$ defined as $\tau=\Sigma A_{i} \tau_{i}$, with $A_{i}$ the relative amplitude of component $i$. As shown

Table 2 Fluorescence lifetime of the samples in chloroform

\begin{tabular}{llcccc} 
Sample & $\tau_{1} / \mathrm{ns}$ & $\tau_{2} / \mathrm{ns}$ & $\tau_{3} / \mathrm{ns}$ & $\tau / \mathrm{ns}^{\mathrm{b}}$ & $\chi_{\mathrm{R}}{ }^{2 / \mathrm{ns}^{\mathrm{c}}}$ \\
\hline P-2,7 & $0.17(0.18)^{\mathrm{a}}$ & $1.54(0.71)$ & $6.30(0.11)$ & 1.82 & 1.14 \\
$\mathrm{P}-3,7$ & $0.17(0.21)$ & $1.50(0.70)$ & $5.33(0.09)$ & 1.57 & 1.08 \\
$\mathrm{P}-4,7$ & $0.19(0.23)$ & $1.46(0.64)$ & $5.85(0.13)$ & 1.74 & 1.13 \\
P-9,7 & $0.17(0.20)$ & $1.17(0.59)$ & $3.35(0.21)$ & 1.43 & 1.18 \\
$\mathrm{M}-3,7$ & $1.44(1.0)$ & & & 1.44 & 1.18 \\
\hline
\end{tabular}

${ }^{\mathrm{a}}$ The data in the parentheses are the relative amplitudes. ${ }^{\mathrm{b}}$ Mean lifetime $\tau$ is defined as $\tau=\sum A_{i} \tau_{i}$, where $A_{i}$ is the relative amplitude of component $i$. ${ }^{c} \chi_{\mathrm{R}^{2}}$ is the difference between the measured data and the fitted function and can be used to judge the goodness-of-fit. 
in Table 2 , the $\tau$ value of P- $m, 7$ decreases with increasing the spacer length. This result supports the physical picture of that the longer spacer can better decouple the interference between the biphenyl group and the backbone. For P-9,7, the fitting data give the dominant lifetime $\tau_{2}$ of $1.17 \mathrm{~ns}$, which is even $0.27 \mathrm{~ns}$ shorter than that of M-3,7. This observation cannot be well explained at this moment. However, the mean lifetime $\tau$ of P-9, 7 is almost identical to that of M-3,7. This coincidence suggests that the overall fluorescence behavior of the biphenyl in P-9,7 is similar to that of the monomer, which is also the observation obtained from the steady state fluorescence measurement.

\section{Conclusions}

The fluorescence behaviors of a series of biphenyl containing SCLCPA with different lengths of flexible spacers were investigated in various solvents. The fluorescence intensity decreases with decreasing the spacer length from 9 to 2 methylene units, which may be related to the increasing of the local concentration of biphenyl groups. The solvent effect indicates that the interaction between the solvents and the biphenyl groups is strengthened with increasing of the orientation polarizability of the solvents. Time-resolved fluorescence spectra show that the decay of the monomer can be fitted with a single exponential decay, but the polymers demonstrate a triple-exponential decay including three pathways, of which the fastest one is related to the molecular quenching caused by the high local concentration and the slowest one can be ascribed to the rotational restriction of the biphenyl groups.

\section{References}

1 Burroughes, J. H.; Bradley, D. D. C.; Brown, A. R.; Marks, B. N.; Mackay, K.; Friend, R. H.; Burn, P. L.; Holmes, A. B. Nature, 1990, 347: 539

2 Pei, Q. B.; Yu, G.; Zhang, C.; Yang, Y.; Heeger, A. J. Science, 1995, 269: 1086

3 Grem, G.; Leditzky, G.; Ullrich, B.; Leising, G. Synthetic Metals, 1992, 51: 383

4 Liu, J. Z.; Lam, J. W. Y.; Tang, B. Z. Chem. Rev., 2009, 109: 5799

5 Akagi, K. Chem. Rev., 2009, 109: 5354

6 Lauchlan, L.; Etemad, S.; Chung, T. C.; Heeger, A. J.; MacDiarmid, A. G. Phys. Rev. B, 1981, 24: 3701

7 Carter, P. W.; Porter, J. D. Phys. Rev. B, 1991, 43: 14478

8 Lee, W. E.; Kim, J. W.; Oh, C. J.; Sakaguchi, T.; Fujiki, M.; Kwak, G. Angew. Chem. Int. Edit., 2010, 49: 1406

9 Han, C. C.; Balasubramanian, A. J. Polym. Sci. Part A-Polym. Chem., 2008, 46: 5483

10 Dong, Y. P.; Lam, J. W. Y.; Tang, B. Z. Polym. Mater. Sci. Eng., 2001, 84: 616
11 Jim, C. K. W.; Qin, A. J.; Lam, J. W. Y.; Haußler, M.; Tang, B. Z. Polymeric Materials: Science and Engineering, 2007, 96: 414

12 Qin, A. J.; Jim, C. K. W.; Tang, Y. H.; Lam, J. W. Y.; Liu, J. Z.; Mahtab, F.; Gao, P.; Tang, B. Z. J. Phys. Chem. B, 2008, 112: 9281

13 Scherf, U.; Skothein, T. J.; Elsembaumer, R. L.; Reynolds, J. R. Handbook of conducting polymers. 2nd ed. New York: M. Dekker, 1998

14 Huang, H. W.; Horie, K.; Yamashita, T.; Machida, S.; Sone, M.; Tokita, M.; Watanabe, J.; Maeda, Y. Macromolecules, 1996, 29: 3485

15 He, X. R.; Liu, H. B.; Wang, N.; Ai, X. C.; Wang, S.; Li, Y. L.; Huang, C. S.; Cui, S.; Li, Y. J.; Zhu, D. B. Macromolecular Rapid Communications, 2005, 26: 721

16 Lam, J. W. Y.; Tang, B. Z. Accounts of Chemical Research, 2005, 38: 745

17 Lam, J. W. Y.; Tang, B. Z. J. Polym. Sci. Part A-Polym. Chem., 2003, 41: 2607

18 Lam, J. W. Y.; Dong, Y. P.; Law, C. C. W.; Li, Z.; Sun, J. Z.; Chen, H. Z.; Zheng, Q.; Kwok, H. S.; Wang, M.; Feng, X. D.; Shen, J. C.; Tang, B. Z. Macromolecules, 2005, 38: 3290

19 Lam, J. W. Y.; Qin, A. J.; Dong, Y. P.; Lai, L. M.; Haussler, M.; Dong, Y. Q.; Tang, B. Z. J. Phys. Chem. B, 2006, 110: 21613

20 Ye, C.; Xu, G. Q.; Yu, Z. Q.; Lam, J. W. Y.; Jang, J. H.; Peng, H. L.; Tu, Y. F.; Liu, Z. F.; Jeong, K. U.; Cheng, S. Z. D.; Chen, E. Q.; Tang, B. Z. J. Am. Chem. Soc., 2005, 127: 7668

21 Geng, J. X.; Zhao, X. G.; Zhou, E. L.; Li, G.; Lam, J. W. Y.; Tang, B. Z. Mol. Cryst. Liq. Cryst., 2003, 399: 17

22 Yu, Z. Q.; Liu, J. H.; Zhu, C. Z.; Chen, E. Q.; Lam, J. W. Y.; Tang, B. Z. Acta Polym. Sin., 2010: 783

23 Huang, Y. M.; Lam, J. W. Y.; Cheuk, K. K. L.; Ge, W. K.; Tang, B. Z. Macromolecules, 1999, 32: 5976

24 Huang, Y. M.; Ge, W. K.; Lam, J. W. Y.; Tang, B. Z. Appl. Phys. Lett., 1999, 75: 4094

25 Yu, Z. Q.; Liu, J. H.; Yan, J. J.; Liu, X. B.; Liang, D. H.; Lam, J. W. Y.; Dong, Y. P.; Li, Z. C.; Chen, E. Q.; Tang, B. Z. Macromolecules, 2007, 40: 8342

26 Lam, J. W. Y.; Kong, X. X.; Dong, Y. P.; Cheuk, K. K. L.; Xu, K. T.; Tang, B. Z. Macromolecules, 2000, 33: 5027

27 Mataga, N.; Kaifu, Y.; Koizumi, M. Bull Chem. Soc. Jpn., 1956, 29: 465

28 Lippert, V. E. Z. Electrochem, 1957, 61: 962

29 Lackwicz, J. R. Principles of fluorescence spectroscopy. 2nd ed. New York: Plenum Press, 1999

30 Ren, Y.; Dong, Y. Q.; Lam, J. W. Y.; Tang, B. Z.; Wong, K. S. Chem. Phys. Lett., 2005, 402: 468 